\title{
Horizontes imaginativos e o aquém e além
}

\author{
Vincent Crapanzano
}

\section{Distinguished Professor of Anthropology and Comparative Literature at the Graduate Center of the City University of New York}

\begin{abstract}
RESUMO: $\mathrm{O}$ autor desenvolve as noçôes de horizontes imaginativos e de liminaridade, travessia, meio-termo, fundamentos de uma proposta de antropologia da imaginação. Lança seu olhar às dimensões ignoradas da experiência, embora considere imprecisão e obscuridade como componentes necessários a toda experiência, ao pensamento e à percepção. Indica as diferentes concepções do entre, pensando, por exemplo, os tempos e espaços intersticiais $(m a)$ na estética tradicional japonesa ou o barzakh no misticismo sufi. Questiona os nossos pressupostos quanto à natureza das relaçôes, mediante uma releitura da teoria da liminaridade de Victor Turner.
\end{abstract}

PALAVRAS-CHAVE: antropologia da imaginação, horizontes imaginativos, liminaridade, experiência, Victor Turner.

Este artigo divide-se em duas partes principais. ${ }^{1}$ A primeira desenvolve a noção de horizontes imaginativos e o papel teórico que acredito deva desempenhar nas ciências humanas. A segunda examina o aquém e além, ${ }^{2}$ o liminar e as travessias que ocorrem nos ritos de passagem e em outros movimentos sociais. Mediante o exame do intersticial na estética japonesa e no misticismo sufi, ela chama atenção para alguns de nossos pressupostos quanto à natureza das relaçóes. Discuto tais pressupostos como estão exemplificados na teoria da liminaridade de Victor Turner. 
Ao revelelar uma outra perspectiva, um outro horizonte possível de compreensão, a discussão reporta à primeira parte deste artigo.

Muito se tem escrito nos círculos acadêmicos em anos recentes sobre divisas, limites e fronteiras, sobre seu reforço, sua supressão, dissolução e porosidade, sobre idas e vindas através deles, sobre transmigração, tudo supostamente afetado e efetuado por conexões pela web, pelo transnacionalismo e pela globalização de nossa estipulada pós-modernidade. Embora reconheça a importância de divisas, limites e fronteiras geopolíticos, a violência que inspiram, as ciladas que produzem, o doloroso deslocamento que causam e os controles que provocam, não trato deles neste artigo. Não me ocuparei do movimento - ou não-movimento - de pessoas através de linhas constituídas legalmente ou em domínios de cultura, língua e poder institucionalizado nitidamente marcados. Antes, as fronteiras me interessam como horizontes que se ampliam da insistente realidade do aqui e agora para aquele espaço ou tempo optativos - o espaço-tempo - do imaginário. É esse âmbito que nos dá uma folga, às vezes dolorosa e angustiante, às vezes prazerosa e apaziguadora, do aqui e agora em toda sua viscosa imediação. Permite-nos escapar da insistente atração da realidade. Embora estar preso à realidade imediata seja associado às culturas primitivas em nossas mitologias etnocêntricas inteiramente questionáveis, que salientam a primazia da vida instintiva deles e a sublimação, de fato, a eterealização, de nossa condição civilizada, todos nós, em algum momento, fomos tão consumidos pela realidade a ponto de perdermos a paciência, a consciência de nós mesmos e de nossos limites. Supomos, acertadamente, creio, que a distância que nos define nasce de nossa habilidade de representar simbolicamente o mundo, inclusive nós mesmos. O que parece escapar a esse acento no simbólico é a relação deste com a possibilidade imaginativa - com a esperança, com o optativo, com os modos - como o subjuntivo, concebido por nossas gramáticas. 
Revista de Antropologia, São Paulo, USP, 2005, v. 48 No 1.

Ao contrário das divisas, que podem ser cruzadas (a menos que estejam fechadas), e dos limites, que podem ser transgredidos, as fronteiras, conforme estou empregando a palavra, não podem ser atravessadas. Elas marcam uma mudança de registro ontológico. Postulam um além que é, por sua natureza íntima, inacessível de fato e de representação. Interesso-me pelo papel do que está situado além do horizonte, pelas possibilidades que oferece, pelos desejos lícitos e ilícitos que desencadeia, pelos jogos de poder que sugere, pelo terror que pode causar - a incerteza, a sensação de contingência, de acaso -, pela exaltação, pelo frêmito com o desconhecido que pode provocar. Imaginado, sonhado, projetado, calculado, profetizado - logo, construído -, o além sempre depende de como o encaramos. Nossas imagens, sonhos, projeçōes, cálculos e profecias podem dar forma e substância ao além, mas, ao fazê-lo, destroem-no; pois, enquanto o constroem, garantem seu deslocamento. E esse deslocamento abala nossas premissas acerca da realidade, base sobre a qual nossas construções são feitas. Embora fundacional, não está imune a nossas imagens do além. Assim, estou particularmente interessado nas vias paradoxais pelas quais a irrealidade do imaginário imprime o real na realidade e por que o real da realidade compele a irrealidade do imaginário. Essas vias não podem ser separadas. São como amantes que, de tão emaranhados, tornam qualquer delimitação de um corpo - ou alma - singular quase arbitrária.

Examinarei a imaginação por meio de um tropo - o do arrière-pays, do sertão, e de seus correlatos, o além e o alhures. Utilizo o termo arrièrepays para relembrar o trabalho do poeta e crítico francês Yves Bonnefoy, cujo livrinho L'arrière-pays (1982) é a inspiração para minhas reflexões de uma antropologia da imaginação. Para Bonnefoy, o sertão evoca as dimensões da experiência que se situam além da percepcão imediata de um objeto, de uma paisagem. Incluem a ansiedade que ele sente em uma travessia: "Lá, a dois passos do caminho que não trilhei e do qual já 
me distanciei, sim, é lá que se abre uma terra de essência mais elevada, onde poderia ter morado e que, desde então, perdi” (p. 9). É uma terra de pura possibilidade, de desejo e medo.

O além é como as trevas: não pode ser contido. Ele escapole - para aparecer de novo exatamente quando se pensava, para alívio ou desespero, que havia sido eliminado. Bonnefoy insiste que o arrière-pays é inacessível, inexistente - como todo objeto da imaginação, é ausente, inexistente, uma negação, um não-ser.

O que torna a inacessibilidade do sertão assustadora é menos a inacessibilidade que seu papel determinante em nossa percepção daquilo que, de modo ingênuo, tomamos por acessível - daquilo que efetivamente percebemos, vivenciamos, tocamos e sentimos. Imaginada melhor ainda, imaginável -, ela permanece elusiva. Como nota o filósofo Edward Casey (1976, p. 7): "De fato, estritamente falando, não observamos o que imaginamos, pois não estamos em condições de submeter objetos e eventos imaginados ao exame minucioso que pode ser administrado àquilo que percebemos". É esse caráter elusivo, essa ausência determinante do acessível, que é assustadora: pois o que percebemos sempre é determinado - até certo ponto - pela ausência, aquela presença imaginada. $\mathrm{O}$ que nos amedronta é mais que a contingência. É o artifício de factualidade, de nosso empirismo, de nosso realismo, pelos quais nos cegamos a nós mesmos - muitas vezes, por meio de disparatadas metodologias da verdade e de ingênuas filosofias positivistas. Velhas conhecidas de todos nós.

Temos de perguntar, contudo, se há alguma razão para que nos assustemos com o sertão, com a possibilidade imaginativa que ele oferece e nega, com (a impossibilidade de) ir ao outro lado? Podemos não sentir prazer com sua irrealidade, com sua possibilidade, o jogo que propicia? Estamos cultural e historicamente vinculados ao medo e à ansiedade perante a possibilidade imaginativa? Perante a ausência - o não-ser - 
que atribuímos ao imaginário? Somos vítimas de uma epistemologia puritana da presença? Ou esses medos, essas angústias, são um componente essencial da condição humana? Eu não sei. Mas posso imaginar e, na verdade, conheço o prazer que a possibilidade oferece, a libertação, a fuga que proporciona. Incomoda-me a banalidade, o caráter repetitivo, de nossos enunciados sobre o sertão. Conforta-me seu contínuo deslocamento o domínio que recusa.

Reconhecendo os horizontes imaginativos e o sertão acolá, desejo oferecer uma crítica de alguns pressupostos empíricos comuns. Não estou descartando o empirismo de per si nem a ciência, a ciência antropológica, mas uma apropriação específica do empirismo (da realidade) que nega ou, ao menos, ignora uma importante dimensão da experiência humana - bem conhecida de todos nós. Não estou advogando uma veneração ao irracional, ao irreal, à imaginação. Meu objetivo é mais mundano. Como o filósofo William James, desejo atentar para aquela dimensão da experiência que, por resistir à enunciação - com efeito, desaparece ao ser enunciada -, tem sido ignorada de fato. Em seu apelo para reintegrar "o vago e inarticulado ao lugar que lhe cabe em nossa vida mental", James notou que "as imagens precisas da psicologia tradicional compõem apenas a menor parte de nossas mentes, enquanto estas realmente vivem" (1992, p. 164-65). Ele salientou que "o significado, o valor da imagem está todo neste halo ou penumbra que a rodeia ou acompanha - ou antes, que se lhe funde e torna-se sangue de seu sangue, carne de sua carne". O halo, a penumbra - prefiro a aura - que rodeia toda experiência, toda percepção e toda compreensão pode apenas ser evocado. Impreciso, obscuro, ele é um componente necessário, creio, de qualquer pensamento, percepção e experiência.

Fenomenólogos relacionariam o que chamo de horizonte imaginativo da percepção à periferia da consciência, aos limites externos de nossa atenção, como um pano de fundo. Insistiriam, entretanto, como faz 
Husserl, que a periferia é simplesmente uma extensão do mundo percebido - e não do imaginado. Os psicólogos também insistiriam no alargamento do campo de percepção. Entenderiam-lhe a qualidade antecipatória não como possibilidade imaginativa, mas como algo prélingüístico, pré-verbal, pré-cognitivo, pré-perceptivo. Os "pré", contudo, não eliminam o fato de o próprio horizonte pressupor língua, cognição e percepção. Ele é, nos termos de Jacques Lacan, um precipitado da ordem simbólica. Os "pré", apesar de alegarmos a imediação deles, indicam um adiamento em nossa percepção, nosso pensamento, nossa imaginação e experiência - um adiamento para o que compóe o sertão, não importa o que seja.

Pense em uma paisagem de montanha pintada pelo artista romântico alemão Caspar-David Friedrich. Muitas vezes, como em sua pintura do Reisengenbirge, nossos olhos são conduzidos do primeiro plano para o horizonte, neste caso, para as montanhas coroadas de neve e o céu claro, luminoso. Mesmo em suas paisagens montanhosas mais íntimas, o que vemos no primeiro plano é percebido em função do que está situado além das montanhas: outras montanhas, um vale, uma aldeia, um agricultor lavrando a terra, uma celebração de colheita, um cortejo fúnebre. Não sabemos. Só podemos imaginar. Quando olhamos para o primeiro plano do quadro, contudo, geralmente não imaginamos de um modo concreto o que se situa além das montanhas, mas nossa percepção está, como estava, impregnada de possibilidades imaginativas. Por mais numerosas que aparentem ser, essas possibilidades não são infinitas. A menos que eu esteja empenhado, digamos, em uma paródia pósmoderna consciente de si mesma, imaginando um mundo de carros a buzinar, camponeses a olhar fixamente para computadores, ou fábricas a expelir vapores nocivos, que impediriam qualquer apreciação da paisagem montanhosa nos próprios termos - nossos constructos imaginativos, por mais difusos que sejam, conforme delimitados pelas premis- 
sas românticas de Friedrich, por sua idealização da natureza, pelo sublime evocado por suas montanhas. A relação entre primeiro plano e sertão é, contudo, recíproca. Caso enunciássemos de fato o sertão como uma espécie de fantasmagoria pós-moderna, por certo veríamos a paisagem de Friedrich de um modo diferente.

Poderia dar muitos exemplos de tais horizontes. Nem sempre têm natureza pictórica - visual -, embora, ao menos na cultura euro-americana, o visual esteja intimamente ligado ao imaginário e à imaginação. Aqui, desejo salientar que o escopo dos horizontes imaginários não é limitado apenas por nossas capacidades psicológicas ou por nossas convençôes estéticas, mas também por arranjos socioeconômicos, políticos e culturais. Embora relute em dar exemplos dessas influências, por serem altamente complexas e operarem tanto indireta como diretamente, darei dois breves exemplos de pesquisas de campo que conduzi entre fundamentalistas cristãos nos Estados Unidos $^{3}$ e entre os Harki, aqueles argelinos que tomaram o partido dos franceses na guerra pela independência da Argélia. Desejo salientar aqui o estilo mais que a causa. Como é sabido, os fundamentalistas cristãos esposam uma forte hermenêutica literalista. Como cada palavra da Bíblia é inerrante, eles acreditam que devem ser o mais fiel possível ao sentido literal delas - ao sentido "próprio". Qualquer desvio desse sentido, ou seja, qualquer interpretação figurativa (a menos que a figuração, como tal, esteja marcada com clareza no texto) é perigosa, pois se corre o risco de sacrificar o sentido de Deus pelo de algum intérprete. Os fundamentalistas preocupam-se com o que chamam, à boa moda vitoriana, imaginação depravada. A hermenêutica, como a oração, o auto-exame e a aplicação da Bíblia à vida cotidiana, é uma disciplina criada, entre outras coisas, para controlar a imaginação e a propensão desta para a interpretação alegórica e figurativa. Como cada palavra na Bíblia, segundo a vêm, é inspirada por Deus e, por isso, ligada de modo indelével a todas as outras palavras, qualquer 
desvio do sentido - do sentido literal - da palavra arrisca pôr abaixo toda a compreensão fundamentalista das Escrituras. Seus horizontes estão contidos no interior desse rígido arcabouço hermenêutico. Como isso se relaciona à vida atual nos Estados Unidos, trata-se, claro, de especulação. Sem dúvida, é possível relacionar essa hermenêutica rígida a uma necessidade de estruturação em um mundo ameaçado pelas incertezas inerentes à sociedade capitalista e pela brutalidade relativa do cotidiano, mas, como sugeri, se este for realmente o caso, o nexo causal não é, de modo algum, direto. É mediado, por exemplo, por uma tradição religiosa duradoura que antecede o capitalismo como o conhecemos uma tradição que enfatiza a salvação pessoal e uma intensa relação pessoal com Deus, ao menos com uma das manifestações Dele, Jesus. Podese relacioná-la também ao individualismo - ao individualismo muitas vezes aterrador e contestado promovido pelo capitalismo. Não sei. Prefiro reconhecer a impossibilidade de determinação sem explicitá-la com açodamento e concentrar-me no estilo.

Meu segundo exemplo se refere aos Harki, os argelinos que tomaram o partido dos franceses na guerra pela independência da Argélia. Quando se conquistou finalmente a independência, em 1962, entre 100 e 150 mil dos, no máximo, 250 mil Harki foram mutilados e massacrados pela população argelina em geral. Embora De Gaulle tenha feito de tudo para desencorajar a emigração dos Harki para a França, cerca de 20 mil famílias harki conseguiram fazê-lo e foram encarceradas em campos de prisioneiros por até 16 anos. Sem dúvida, ambivalentes quanto à posição política, traídos e abandonados, do ponto de vista deles, pelos franceses, incapazes de retornarem à Argélia, os Harki são uma população à part - agora, uma população espalhada pela França e estendendose pela terceira geração, unida por traumas coletivizados ao longo das gerações, que são reiterados em histórias ou reconhecidos silenciosamente. Esses traumas - esse trauma (pois, coletivizado, se tornou singular) - 
tornam-se um ponto de referência básico que, gostaria de indicar, restringe as possibilidades imaginativas dos Harki - uma restrição que, sem dúvida, se correlaciona com o status marginalizado deles na França. Cada adversidade é reportada aos maus-tratos que sofreram, que, por reais que tenham sido e sejam, não são, de modo algum, cabais.

Passo agora à segunda parte deste artigo. Em certo sentido, ela decorre diretamente de meu interesse pelo horizonte imaginativo, pois é uma tentativa de inaugurar uma via para pensar sobre a contigüidade, a metonímia e a montagem. Interessa-me especialmente a montagem conforme a entendo, a justaposição, às vezes arbitrária, às vezes inusual, de dois ou mais itens, elementos, imagens ou representaçôes que chama atenção para aspectos desses itens que estavam escondidos ou eram ignorados. Montagens inusuais podem produzir surpresa ou choque, iluminações repentinas, epifanias ou insights e, por isso, podem ser retóricas, estéticas ou terapeuticamente efetivas. Podem ser transgressivas, inquietantes, perigosas e iconoclastas. $\mathrm{O}$ significado que atribuímos às justaposições, claro, é determinado, consciente ou inconscientemente, pelo discurso. Produzindo ansiedade interpretativa, as montagens exigem uma firmeza interpretativa - uma tradução, por exemplo, a um paradigma familiar que produza contentamento. Devo observar, entre parênteses, que a montagem é intrínseca à etnografia, pois o antropólogo conjuga elementos de duas culturas - a cultura em estudo e a cultura de referência. Assim, há uma dimensão iconoclasta importante para a etnografia que é (em meu ponto de vista, infelizmente) reduzida pela etnologia - pela descrição tornada convencional, pela interpretação autorizada, pela explicação científica. Não estou negando agora o valor da interpretação ou da explicação (embora questione o da descrição convencional). Desejo simplesmente indicar-lhes um efeito secundário inevitável, que exige reconhecimento crítico. 
Agora, desejo demonstrar que, ao menos na cultura euro-americana, tendemos a enfatizar antes os elementos que compõem uma relação, incluindo a montagem, do que a própria relação - o aquém e além, o intersticial. É por demais óbvio que elementos compositivos e relações são mutuamente determinantes. E, decerto, não quero envolver-me em uma discussão do tipo quem-veio-primeiro-o-ovo-ou-a-galinha. O que desejo salientar é que em determinadas sociedades, ao menos em alguns de seus domínios, enfatiza-se a própria relação - e o modo pelo qual esta formula e define os elementos que a compóem. Tal ênfase - chamese estilo cognitivo ou perceptivo - afeta não apenas a estética e outras formulações teóricas, mas também é refletida e reflete outros elementos culturais e suas relações sintáticas. Que na cultura euro-americana ao entre preferimos os elementos que o balizam - à relação preferimos os termos que a constituem - pode relacionar-se, por exemplo, à prioridade que damos à palavra - o nome - e ao referente em nossa concepção (popular) de linguagem. Concentramo-nos em categorias e sistemas classificatórios baseados nessas categorias, em vez de em sistemas determinados pela relação e pela sintaxe. Acentuamos a coesão e moderamos a elipse, a interrupcão e a pausa. De modo geral, não lemos em função do silêncio e do não dito. Muitas vezes, choco meus alunos quando peço que considerem um romance como The Awakening [ $O$ despertar], de Kate Chopin, ou algum de Clarice Lispector, sob o aspecto das lacunas entre os capítulos, com efeito, entre os parágrafos e as frases.

Não creio que os japoneses ficassem tão chocados quanto meus alunos norte-americanos. A estética (tradicional) daqueles, profundamente enraizada em sua perspectiva religiosa, enfatiza o intervalo, a lacuna, o silêncio, o entre e o em meio a. No verso encadeado japonês (renga), por exemplo, o efeito estético resulta menos das cenas descritas que do espaço-tempo entre os versos encadeados (Ebersole, 1983, p. 55). "Con- 
centre-se no que não é dito", disse Shinkei (1406-1475), o poeta (Kamparu, 1983, p. 74). Zeami Motokyio (1363-1443), o fundador do teatro nô, afirmou que "os momentos de inação" (sensu tokoro), ocorridos entre (himu), são os mais deliciosos do teatro nô (Pilgrim, 1995, p. 58). "O que o ator não faz tem interesse" (sennu tokoro ga omoshiroki) (Komparu, 1983, p. 73).

Os japoneses chamam esses espaços ou tempos intersticiais de ma. Diz-se que o ma vem do chinês, o caractere que mostra o sol no meio de portão aberto. Originalmente, era usado unicamente para referir-se a espaço mas passou a designar igualmente o tempo. Pode ser traduzido por "espaço, epaçamento, intervalo, lacuna, vão, lugar, interrupção, pausa, tempo, ocasião ou abertura" (Komparu, 1983, p. 70). Tem conotações tanto abstratas como concretas. Um lugar é ma porque é um espaço entre paredes; em música, uma pausa também é ma, porque ocorre entre duas notas (Pilgrim, 1995, p. 56). Roland Barthes (1982) tentou - de um modo por demais afetado e profundamente francês (e, por isso, etnocêntrico) - delinear o ma em sua interpretação pós-estruturalista do Japão. Ele utiliza expressões como "o nada pregnante", "uma reminiscência desmembrada, descentrada, deslocada", um "signo vazio remanescente da fissura do simbólico" para evocar algo que ele não nomeia. Artistas, acadêmicos e arquitetos japoneses defendem que o termo resiste à tradução. Salientam-lhe a ambigüidade, o fato de que, para ser compreendido, se deve levar em conta uma configuração de espaço e tempo, que não podem ser separados um do outro, unicamente japonesa e uma concepção de energia ou poder espiritual ( $k i_{-}$ou chi) que ressoa no interior do espaço-tempo, entre e em meio a. Ele é um cronotopo negativo - um silêncio, um vazio -, não obstante fecundo, que antecipa (e é antecipado por) o espaço-tempo positivo da ação em, digamos, uma peça nô (Komparu, 1983). Ma refere-se, simultaneamente, a algo e a experiência 
desse algo. Não é objetivo nem subjetivo, mas uma coalescência dos dois, pois, visto que o ma desconstrói todos os limites, ele tem (suponho) de eliminar aqueles existentes entre o objetivo e o subjetivo.

Motokiyo observa que é o kokoro - a força espiritual subjacente do ator nô - que produz o deleite da platéia em "momentos de inação". O ator "não relaxa a tensão quando a dança ou o canto chegam ao fim ou em intervalos entre (hima) o diálogo e os diferentes tipos de mímica". Ele conserva sua "firme vontade interior (naishin)", mas não deve tornála aparente, o que equivaleria a agir e, portanto, deixaria de ser inação (Pilgrim, 1995, p. 58-59). Quero destacar uma espécie de relação - chame-se suspense ou tensão dramática - que não se presta a uma análise coloquial. Depende sobremaneira de pausas e silêncios; que fogem à mensuração. Há diferentes silêncios, diferentes pausas; diferentes atitudes em relação a eles. Têm valor qualitativo.

Embora voltadas para palavras, coisas e eventos, para notas musicais, nossas interpretações, seja de um ator representando o papel de Rei Lear ou de um pianista executando uma sonata de Haydn, necessariamente, devem considerar o espaço - o silêncio - entre palavras e notas. Permitimos que essas interpretações ficassem privadas de teorização, o que, em uma época excessivamente teorizada como a nossa, por certo, deve ser tomado como um sintoma de nossa perspectiva epistêmica e de seus efeitos sobre a atenção, ou mesmo sobre a percepção. Deixamos esse silêncio -, que pode ser de tamanha importância hermenêutica, à arte da interpretação. Reconhecemos, claro, a importância do silêncio na interlocução, que é interpretado primordialmente, creio, em termos psicológicos e, apenas de modo secundário, em termos estéticos (salvo quando tratamos de uma comunicação moldada para a apreciação estética, claro). Como o psicanalista, embora de modo menos consciente, observamos os silêncios, as pausas das pessoas com quem conversamos. Nós os lemos como sinais de estados interiores - medo, culpa, cons- 
trangimento, vergonha - e, com muita freqüência, como revelações involuntárias do que se procura ocultar. Em épocas de espírito mais retórico, como na Grécia e Roma antigas, o silêncio foi reconhecido e cultivado como uma figura retórica sob total controle do orador.

Lembro-me de passar horas com meu amigo e mentor marroquino Moulay Abedslem, um velho analfabeto de grande sabedoria espiritual que fazia mortalhas e lavava corpos, discutindo o barzakh - o que está situado entre as coisas, entre as bordas, as divisas e os eventos. Ele o equiparava ao silêncio entre as palavras e aos sonhos. "O sonho está entre a vigília e o sono", disse. Barzakhi é o âmago da filosofia do grande sufi andaluz Ibn al-'Arabi (1165-1240) (ver Chittick, 1989; Corbin, 1958). Moulay Abedslem ouvira falar dele, mas não tinha conhecimento preciso de seu pensamento e certamente não relacionava a própria compreensão do barzakhi à de al-Arabi. Para este, a imaginação (alkhayal) é um termo intermediário que resiste à definição. Em alguns momentos, parece estar entre o mundo espiritual e o material; em outros, entre o ser e o nada, como algo equivalente à existência. $\mathrm{O}$ importante é que a imaginação é uma "realidade" intermediária, ambígüa por natureza e melhor descrita como "nem isso nem aquilo ou tanto isso quanto aquilo". É barzakh, que al-'Arabi descreve como:

Algo que separa [fâsil] duas outras coisas, sem nunca pender para um lado [mutatarrif], como, por exemplo, a linha que separa a sombra da luz do sol... O barzakhi é algo que separa o conhecido do desconhecido, o existente do inexistente, o negado do afirmado, o inteligível do ininteligível. (Chittick, 1989, p. 117-18)

Ele tem grande poder. É um termo inteligível, o filósofo sufi nos diz, mas é apenas imaginação. Ele insiste na transitoriedade - as mutações contínuas - da realidade mediadora da imaginação, ou seja, o que 
normalmente tomamos pela realidade cotidiana, o mundo como o conhecemos. Ibn al-'Arabi não desenvolve, contudo, uma estética fundada no entre, como os japoneses fizeram. Adotou uma atitude marota em relação ao barzakh, ao mesmo tempo, jocosa e imensamente séria, o que é inteiramente estranho à variante japonesa de ma. Essa atitute permitiu-lhe trazer à baila o artifício do mundo como o conhecia - presunção humana. Para o filósofo sufi, barzakhi, o jogo retórico que oferece, possibilitou-lhe insinuar outra realidade - outras realidades - a que, mediante disciplina mística ao menos, tem-se aceso.

Esforcei-me em descrever diferentes atitudes com respeito ao entre, pois, embora nossa perspectiva epistêmica peculiar tenda a ignorá-lo, ele é na realidade uma "arena" de singular importância social, cultural e psicológica. Ficamos ansiosos, como insistem os existencialistas, perante qualquer indício do não-ser. Podemos ignorá-lo; podemos evitá-lo; podemos ocultá-lo. Podemos enunciá-lo tangencialmente. Também podemos conceber o não-ser esteticamente, como os japoneses fazem com o $m a$, atribuindo-lhe, assim, valor positivo; ou podemos jogar com ele retoricamente, como Ibn al-AArabi faz com o barzakh, para evocar a dimensão imaginária - sempre, de algum modo, uma negação - do que tomamos por realidade. Concentramo-nos, como insiste Heidegger (1979, p. 340), no que é, sem levar em conta o fato de o Nada ser um tipo de pano de fundo projetivo para o que é: "o Nada é o que torna possível a revelação de nossa existência humana como ela é”. Não desejo, aqui, discutir a noção heideggeriana do Nada, apenas observar que o suspense - estar em suspensão, pender, flutuar, pairar, ascender, scwebwen - é um componente essencial do terror que revela o Nada. "Aterrorizados, ficamos em 'suspense' (wir schweben)" (Heidegger, 1979, p. 336). Quero salientar o suspense - o risco - da passagem. Desejo sugerir que em todas essas travessias há sempre um momento, assintótico, que está simultaneamente dentro e fora do tempo e do espaço, como normal- 
Revista de Antropologia, São Paulo, USP, 2005, v. 48 No 1.

mente os conhecemos. São fundamentais à vida social, aos seus procedimentos mais básicos: troca, passagem, reprodução e transformação.

Estou interessado, portanto, nos perigos de atravessar o limiar - o limen - e, para utilizar as palavras do antropólogo Victor Turner (1969, 1974), os estados liminares que estão associados a essa travessia. Ibn al'Arabi iria chamá-los de barzakh, mas daria ao termo um sentido epistêmico que Turner, dada sua epistemologia, não pode. $\mathrm{O}$ modelo de Turner é basicamente o modelo tripartite do rite de passage de Van Gennep (1960): separação, margem e incorporação. Ele e outros ampliaram o modelo dos ritos concernentes a crises na vida de um indivíduo para aqueles da sociedade como um todo. Estes incluiriam ritos preparatórios para a guerra, cerimônias de primeira frutificação, colheita e chuva, que marcam a passagem da escassez para a abundância, e rituais de posse, como coroações, que, embora centrados em um indivíduo, são eminentemente sociais na orientação e nos efeitos. Turner (1974, cap. 1) amplia mais ainda o modelo, aplicando-o a períodos de reparação de conflitos sociais, que chama de dramas sociais. $\mathrm{O}$ centro de sua atenção é a liminaridade - a margem -, que considera uma "situação interestrutural" e é entendida como processo e devir. Julga o aquecimento da água até a fervura, ou a modificação de uma pupa de lagarta em mariposa "analogias apropriadas" de transição e transformação. Não está particularmente interessado em pontuar o liminar - em suas disjunções internas - e em como este efetua e é afetado pelo momento final, definidor, da transição. ${ }^{4}$

Ao contrário de Turner, quero atentar nas disjunções rituais, sociais e culturais e no momento, que cada vez mais se reduz mas nunca desaparece por completo, da diferença que resiste à enunciação. Eles são apenas executados e geralmente ignorados, embora possam ser exibidos em rituais dilatados e repetitivos, no drama, na literatura e na música. São os momentos definidores dos ritos de passagem, das cerimônias de cura, 
das investiduras de poder e autoridade sagradas e seculares e transições corriqueiras de um registro experiencial, por exemplo, a vigília, a outro, por exemplo, o sonho, o transe ou o simples adormecer. São arriscados $\mathrm{e}$, às vezes, perigosos, embora o perigo e o risco que acarretam sejam em regra limitados pela convenção, repetição e sanção. Podem marcar uma mudança de status dos participantes; muitas vezes, envolvem a troca de objetos, reais ou simbólicos, que pairam “despossuídos” por um instante. Com efeito, há, em qualquer troca, um momento disjuntivo no qual o objeto não é dado nem recebido e em que os participantes ainda não são doadores nem receptores. Há sempre o risco de desistência e a conseqüente ruptura da relação. E há momentos, os mais dramáticos de todos, em que os participantes são apanhados em um entre que não podem sequer definir - em que não há travessia.

$\mathrm{Na}$ maioria das vezes, os momentos que desafiam a enunciação permanecem um paradoxo: para cada travessia, há sempre um momento em que não se está num lado nem de outro, em que não se é o que era nem o que será; pois, uma vez que são discriminados, o contígüo nunca os atinge. Fica-se em suspensão - pairando eternamente de permeio. (Talvez por isso os japoneses imaginam a si mesmos como preenchidos de energia.) Tome-se o casamento, por exemplo. Há sempre o mais breve dos momentos, quando não se é mais solteiro e tampouco se é casado ainda. Um casal está diante do altar, um sacerdote está prestes a declarálos marido e mulher, mas ainda não o fez ou apenas proferiu as primeiras palavras da declaração. O casal ainda está solteiro? Embora, tecnicamente, não estejam casados, hesitaríamos em dizer que ainda são solteiros. De modo mais extremo, mais absurdo: o sacerdote declarouos marido e mulher, mas eles (ou as testemunhas) ainda não ouviram ou escutaram - as palavras. Ainda são solteiros? Casados? A mudança de status é instantânea; ou seja, ela ocorre em um instante e, nesse instante, sempre há um risco. Ainda que breve, sempre há a possibilidade de a 
noiva ou o noivo fugir; o sacerdote parar; uma testemunha morrer; um dos convidados levantar uma objeção. Essa é a substância do melodrama, mas ela reflete o suspense e o risco de qualquer transição social. (Descobri que a maioria das pessoas - incusive eu mesmo - não é capaz de recordar tais momentos.)

Turner (1967, p. 96) relaciona os símbolos de morte, decomposição e menstruação (muitas vezes, tida como a perda de um feto), que são com frequiência vinculados aos iniciados, ao fato de estes não serem mais classificados. Estruturalmente "mortos", podem ser tratados como cadáveres; denegridos; sepultados; obrigados a deitar, imóveis, na posição habitual dos defuntos, e forçados a viver "com mascarados monstruosos que representam, inter alia, os mortos, ou, pior ainda, os mortos-vivos”. Por não estarem ainda classificados, associam-se os neófitos a símbolos de gestação e parto. Podem ser tratados como embriões, neonatos ou crianças de peito. Os dois conjuntos de símbolos, diria, são inextricáveis, ocultam ao revelar, revelam ao ocultar o momento de transição que resiste a ser enunciado. Paradoxalmente, é o simbolismo do nascimento e do renascimento que media a transição, na maioria das vezes, e encobre a disjunção, por sua vez, exposta pela imbricação do simbolismo da morte e do nascimento. Porquanto o nascimento media a oposição entre nascimento e morte, as cartas são sempre embaralhadas em favor dele - da afirmação do ser sobre a não-ser, da continuidade sobre a descontinuidade.

O que há de interessante nesses momentos de transição é que sua liminaridade de vida curta está muitas vezes encravada na liminaridade dilatada, em que a transição final é, como foi, ensaiada em uma série de minitransições: as provas, testes e provaçóes das cerimônias de puberdade, por exemplo. Caracterizam-se por múltiplas repetições em vários registros. Turner descreveu essas longas passagens e, embora reconhecesse sua qualidade dramática, em meu juízo, não avaliou plenamente o 
modo como elas atingem o clímax, o momento da passagem que, em essência, não pode ser enunciado. Ele tendeu, em suas generalizações sobre a liminaridade, como antiestrutura e communitas, a achatá-lo. Freud, sem dúvida, teria visto essas travessias cada vez mais dramáticas como um modo de dominar a ansiedade. Lévi-Strauss talvez as visse como um modo de reduzir a lacuna entre os dois lados da travessia. Eu quero salientar o perigo, a ansiedade e o terror que evocam. Eles, de maneira inconsciente, chamaram atenção para o artifício de nossa compreensão social e cultural ao exporem esses momentos refratários, que escapam a - e correm o risco de destruir - aquela compreensão e suas exigências de coesão e continuidade. Podemos descrever tais momentos com a expressão horror vacui, ${ }^{5}$ com a qual Nietzsche (1967) caracterizou o momento dionisíaco da tragédia grega; ou "abismo" - l'abîme -, tão popular na poesia simbolista francesa; ou não-ser. Mas devemos fazêlo com cuidado, pois elas refletem, como insiste Derrida, nossa insistente ontologia da presença - uma ontologia que, apesar de suas pretensóes universalistas, de modo algum é compartilhada universalmente.

O liminar foi muitas vezes equiparado ao sonho - ao processo primário de pensamento. Ele sugere possibilidades imaginativas que, não necessariamente, estão ao nosso dispor no cotidiano. Por meio de paradoxo, ambigüidade, contradição; de símbolos incomuns, exagerados e, por vezes, grotescos - máscaras, indumentária, estatuetas -; e pela evocação de realidades transcendentes, do mistério e de poderes sobrenaturais, o liminar nos oferece uma visão do mundo, que normalmente não enxergamos, cegados pelas estruturas usuais da vida social e cultural. Turner cita o místico alemão Jakob Böhme: "Em incerteza todas as coisas consistem". Devemos citar igualmente al-'Arabi - ou um sem-número de outros místicos que chamam atenção para os paradoxos de nossa compreensão. Turner escreve: 


\section{Revista de Antropologia, São Paulo, USP, 2005, v. 48 No 1.}

A liminaridade talvez possa ser considerada como o Não de todas as asserções estruturais positivas, mas, em certo sentido, a fonte de todas elas e, mais do que isso, como um reino de pura possibilidade, de onde novas configurações de idéias e relações podem surgir. (1967, p. 97)

Sim, queremos dizer - tamanho é o ethos de nossa criatividade -, mas devemos reconhecer que o liminar também impõe constrangimentos. Ele não é sem estrutura, como Turner algumas vezes afirma, mas, como sustenta em outras, é antiestrutural, ou seja, conforme entendo, sempre está em relação com a estrutura do cotidiano. $\mathrm{O}$ liminar pode estimular a invenção, mas, ainda que pela negação, também afirma a tradição.

À guisa de conclusão, quero destacar um paradoxo no modo como compreendemos o liminar, quanto à imaginação. Se tomamos a imaginação, como fazem Sartre e, à sua maneira, Ibn al-'Arab, como algo que apresenta o que está ausente ou é inexistente, somos obrigados a concluir que expomos essas lacunas, esses momentos disjuntivos do nãoser, que pontuam nossa vida social e cultural, por meio de um atividade que permanece no não-ser de seu objeto - a imagem. A imaginação também nos fornece o brilho, os dispositivos retóricos, as manobras narrativas e as estratégias rituais que ocultam essas lacunas. Expomos o nãoser, como era, por meio de um ato que postula o não-ser, assim como ocultamos esse não-ser por um não-ser que declaramos, ao menos no ritual, ter completude - plenitude. Que é mais "real" que os objetos rituais? Turner poderia chamá-los sacerrima. É a esse paradoxo que se deve a contínua (ainda que repetitiva) elaboração, no ritual e no drama, na literatura e na arte, especialmente e do modo mais puro, na música, do momento assintótico de passagem, que torna as fronteiras imaginativas tão ameaçadoras quanto fascinantes e encantadoras para nós? Tal sub- 
terfúgio, se pode ser chamado assim, é uma fonte de nossa inegável criatividade social e cultural - ou de sua extinção - por meio da repetição e de sua proclamação como verdade última.

\section{Notas}

1 Este artigo, em boa medida, baseia-se nos dois primeiros capítulos de meu novo livro, Imaginative Horizons: An Essay in Literary-Philosophical Anthropology (2004).

2 N. do T.: O autor emprega a expressão betwixt and between - traduzida geralmente por "nem uma coisa nem outra" e que denota estado ou natureza ambígua, indeterminada -, em referência ao ensaio de Victor Turner "Betwixt and Between: The Liminal Period in rites de passage" (in Turner, 1967). Este a utiliza para caracterizar a condição dos indivíduos que, nos ritos de passagem, encontram-se no "estado de transição" ou liminaridade: "Entidades liminares não estão cá nem lá; estão aquém e além [betwixt and between] das posiçôes designadas e dispostas por lei, costume, convenção e cerimonial" (Turner, 1969, p. 95). O tradutor valeu-se de leitura e comentários dos professores Rose Satiko Hikiji e John Dawsey, a quem agradece.

3 Ver Crapanzano (2000) para uma discussão pormenorizada da hermenêutica do fundamentalismo cristão.

4 Ver Crapanzano (1992, p. 260-80) para uma discussão das disjunções intra e extra-ritual. Ver também Taussig (1987, p. 441 ss).

5 N. do T.: Literalmente, horror ao vácuo.

\section{Bibliografia}

BARTHES, R.

Empires of signs, New York, Hill and Wang.

BONNEFOY, Y.

1982

L'arrière-pays, Paris, Gallimard. 
CHITTICK, W.C.

1989 The sufi path of knowledge: Ibn al-'Arabi's metaphysics of the imagination, Albany, State University of New York Press.

CORBIN, H.

1958 L'imagination créatrice dans le soufisme D'Ibn al-Arabi, Paris, Flammarion.

CRAPANZANO, V.

1992 Hermes' dilemma and Hamlet's desire: Essays in the Epistemology of Interpretation, Cambridge, Harvard University Press.

2000 Serving the word: literalism in America from the Pulpit to the Bench, New York, New Press.

2004 Imaginative horizons: an essay in literary-philosophical antropology, Chicago, Chicago of University Press.

EBERSOLE, G.

1983 "The buddhist use of linked poetry in medieval Japan", Eastern Buddhist, $16(2)$.

HEIDEGGER, $M$.

1979 "What is metaphysics?", in BROCK, W. (ed.), Existence and being, South Bend, Ind., Regnery Gateway, p. 325-61.

JAMES, W.

1992 "Psychology: a briefer course", in Writings, 1878-1899, New York, Library of America, p. 1-443.

KOMPARU, K.

1983 The Noh theater: principles and perspectives, New York, John Weatherall.

NIETZSCHE, F.

1967 The birth of tragedy, New York, Vintage.

PILGRIM, R. B.

1995

"Intervals (Ma) in space and time: foundations for a religio-aesthetic paradigm in Japan”, in WEIHSUN FU, C. \& HEINE, S. (eds.), Japan in traditional and postmodern perspectives, Albany, State University of New York Press, p. 55-80. 
TAUSSIG, M.

Shamanism, colonialism, and the wild man: a study in terror and healing, Chicago, University of Chicago Press.

TURNER, V.

The forest of symbols: aspects of Ndembu ritual, Ithaca, Cornell University Press.

1969 The ritual process: structure and anti-structure, Chicago, Aldine.

1974 Dramas, fields, and metaphors: symbolic action in human society, Ithaca, Cornell University Press.

VAN GENNEP, A.

1960

The rites of passage. London, Routledge, Kegan Paul.

ABSTRACT: In this paper, the author develops the notions of imaginative horizons as well as of betwixt and between, liminality and crossing; grounded on them, he propounds an anthropology of the imagination. Despite considering fuzziness, shadowiness as a necessary component of all experience, thought and perception, he focuses on ignored dimensions of reality. Examining the interstitial spaces and times $(m a)$ in traditional Japanese aesthetics or the notion of barzakh in Sufi mysticism, the author stresses different conceptions of the between. Finally, through a rereading of Victor Turner's theorization of the liminal, he calls in question our presuppositions about the nature of relations.

KEY-WORDS: Anthropology of the imagination, imaginative horizons, liminality, experience, Victor Turner.

\section{Tradução de André Pinto Pacheco.}

Aceito em agosto de 2005. 